\title{
26 Research Square \\ Validity of the COPD-6® Device for COPD Screening in the Primary Care Setting of China
}

\section{Shuyun Chen}

State Key Laboratory of Respiratory Disease

Xiaochen Li

State Key Laboratory of Respiratory Disease

\section{Zihui Wang}

State Key Laboratory of Respiratory Disease

\section{Yumin Zhou}

State Key Laboratory of Respiratory Disease

\section{Dongxing Zhao}

State Key Laboratory of Respiratory Disease

\section{Zhuxiang Zhao}

State Key Laboratory of Respiratory Disease

Sha Liu

State Key Laboratory of Respiratory Disease

Pixin Ran ( $\nabla$ pxran@gzhmu.edu.cn )

Guangzhou Institute of Respiratory Health, The State Key Laboratory of Respiratory Disease, The First Affiliated Hospital of Guangzhou Medical University https://orcid.org/0000-0001-6651-634X

\section{Research}

Keywords: COPD screening, airflow limitation, FEV1, FEV6, lung function

Posted Date: November 23rd, 2020

DOl: https://doi.org/10.21203/rs.3.rs-112098/v1

License: (c) (1) This work is licensed under a Creative Commons Attribution 4.0 International License. Read Full License 


\section{Abstract}

Background: The use of simple and affordable screening tools for chronic obstructive pulmonary disease (COPD) is limited. We aimed to assess the validity of a handheld expiratory flow meter (COPD- $6^{\circledR}$, Vitalograph Ltd., Ireland) for COPD screening in Chinese primary care settings.

Methods: In our cross-sectional study, subjects were randomly selected in eight primary care settings. Testing with the Vitalograph-COPD- $6{ }^{\circledR}$ and conventional spirometry were sequentially performed on subjects. The correlation between COPD- $6^{\circledR}$ and conventional spirometry was determined. Validity was analyzed by the area under the receiver operator characteristic curve (AUC) of the forced expiratory volume in one second $\left(\mathrm{FEV}_{1}\right)$ / forced expiratory volume in six seconds $\left(\mathrm{FEV}_{6}\right)$ that used to detect airway obstruction. The sensitivity, specificity, predictive values, and likelihood ratio were calculated according to different $\mathrm{FEV}_{1} / \mathrm{FEV}_{6}$ cut-off points.

Results: 229 subjects $(15.4 \%)$ were diagnosed with airflow limitation by standard spirometry. $\mathrm{FEV}_{1}, \mathrm{FEV}_{6}$, and $\mathrm{FEV}_{1} / \mathrm{FEV}_{6}$ measured by COPD- ${ }^{\circledR}$ were correlated with $\mathrm{FEV}{ }_{1}, \mathrm{FVC}$, and $\mathrm{FEV}{ }_{1} / \mathrm{FVC}$ measured by spirometry $(r=0.889,0.835$ and $0.647, p<0.001)$, respectively. AUC of the $F_{E V} / F F_{6}$ to determine airflow obstruction was 0.857 ( $95 \% \mathrm{Cl}: 0.826$ to 0.888 ). No significant difference of AUC was observed between the symptomatic group and the asymptomatic population ( $A U C=0.869$ vs. $0.843, P=0.425$ ). A similar phenomenon was found in the AUC of smokers and never-smokers ( $A U C=0.862$ vs.0.840; $P=0.515$ ). The value of AUC was largest (i.e., 0.80 ) when the cut-off point for $\mathrm{FEV}_{1} / \mathrm{FEV}_{6}$ was 0.77.

Conclusions: The handheld COPD- $6{ }^{\circledR}$ could be used as a pre-screening device on early diagnosis of COPD in Chinese primary care settings.

\section{Introduction}

Characterized by persistent airflow limitation, chronic obstructive pulmonary disease (COPD) was a highprevalence disease with heavy mortality and morbidity burden[1, 2]. It's reported that COPD caused $2.6 \%$ of global disability-adjusted life years (DALYs) and 3.2 million death worldwide in 2015[3]. Airflow limitation is defined as a post-bronchodilator forced expiratory volume in 1 second $\left(\mathrm{FEV}_{1}\right) /$ forced vital capacity $(\mathrm{FVC})<0.7$ and regarded as the essential test for the diagnosis of COPD[4]. In COPD patients, persistent airflow limitation might lead to the substantially impaired quality of life and higher risk of premature death[5].

For the long-term of the asymptomatic phase, countless COPD patients remained undiagnosed until the onset of severe symptom[6,7]. Early symptoms of COPD are subtle and unrecognized for numbers of patients. The reduction of lung function was usually dramatic and irreversible when COPD was diagnosed for the first time. What is more, the reduction of lung function could lead to poor health-related quality of life[7-9]. Although undiagnosed COPD patients usually have fewer exacerbations than severe COPD patients, they also require amount of medical care services for exacerbation events that should 
have been avoided[10]. Therefore, misdiagnosis of COPD could also bring considerable health burden. In this context, early screening for COPD was regarded as a potential method to reduce the burden of morbidity and mortality of patients[7]. However, the problem of underdiagnosis on COPD is obvious (ranging from 72-93\%)[7]. There were increasing interests in improving the early detection of COPD in the primary care setting during the last decade. Spirometry is a well-established tool for quantifying airflow limitation and the diagnosis of patients with COPD[5]. However, there are several seasons for conventional spirometry in primary care practice. First, the expensive cost of the machine has limited technology extension. Second, shortness of professional training led to the unreliable quality of test and interpretation in primary care settings[11-14]. The U.S. Preventive Services Task Force and the American College of Physicians recommend that spirometry should not be used to screen for airflow limitation in individuals without respiratory symptoms. The use of conventional spirometry in primary care setting may result in a waste of medical resources and an overestimation of COPD burden[15, 16].

The use of simple and affordable screening tools is limited. Forced expiratory volume in 6 seconds $\left(\mathrm{FEV}_{6}\right)$, a more easily achieved and reproducible measurement, has been regarded as an alternative to $F V C[17]$. Primary studies had found that $\mathrm{FEV}_{1} / \mathrm{FEV}_{6}$ could be used as a substitute for the $F E V_{1} / F V C$ in the diagnostic screening for COPD[18]. There is a strong correlation between $\mathrm{FEV}_{1} / \mathrm{FVC}$ and $\mathrm{FEV}_{1} / \mathrm{FEV}_{6}[19-$ 22]. Consequently, inexpensive, user-friendly, and hand-held devices for measuring $F E V_{1}$ and $F_{E V}$ have $_{6}$ been produced to detect COPD in primary care[23-29].

Vitalograph COPD-6® (model number 4000, Vitalograph Ltd., Ireland) is one kind of emerging devices. Primary care physicians can obtain $\mathrm{FEV}_{1}, \mathrm{FEV}_{1} \%$ predicted, $\mathrm{FEV}_{6}, \mathrm{FEV}_{6} \%$ predicted, $\mathrm{FEV}_{1} / \mathrm{FEV}_{6}$, and lung age through $\mathrm{COPD}-6{ }^{\circledR}$ test. It can also provide the diagnosis of airflow limitation and severity classification according to the Global Initiative for Chronic Obstructive Lung Disease (GOLD) guideline[5]. However, no study has examined the validity of COPD-6® in low or middle-income countries, including China. Furthermore, the best cut-off value using to define airflow limitation remains uncertain in China. Therefore, we designed this study to assess the validity of COPD- $6 \AA$ device for COPD screening in primary care settings in China.

\section{Methods}

\section{Setting}

With the socioeconomic differences between rural and urban regions, two urban streets and two rural communities were randomly selected from an urban region (Guangzhou, Guangdong Province) and a rural region (Lianping, Guangdong Province), respectively. Two primary care settings were selected from each of the street/community mentioned above. Finally, eight primary care settings were involved in our study.

\section{Study Population}


The sample size of each age group was calculated according to the percentage of the population aged $\geq$ 40 years reported in the latest census. In selected primary care settings, 200 residents from four different age groups $(40-49,50-59,60-69$, and $\geq 70)$ was required. People engaged in these projects should had given informed consent before conventional spirometry and COPD-6® testing.

There were several exclusion criteria for spirometry and COPD-6® testing to avoid : (1) medical history of thoracic, abdominal or eye surgery in previous three months; (2) medical history of acute heart events (e.g., angina, acute myocardial infarction, and malignant arrhythmia) in previous three months; (3) hospitalizations for heart diseases in previous one month; (4) patients with active pulmonary tuberculosis disease or taking anti-tuberculosis drugs; (5) patients with a history of retinal detachment; (6) patients with new tumor diagnosed or undergoing a tumor treatment; (7) patients with cognitive impairment or mental disorder; (8) high paraplegia or thoracic deformity; (9) women during pregnancy or lactation.

\section{Data Collection}

\section{Procedures}

Unique ID number was assigned to each participant. A standardized questionnaire, COPD-6® testing, and conventional spirometry were conducted for each participant sequentially.

\section{COPD-6® testing}

COPD-6® testing was executed by well-trained primary care physicians. At least three maneuvers were performed for each participant without the use of bronchodilator. Results should have met criteria for acceptability (forced expiration for at least $6 \mathrm{~s}$ ) and reproducibility (at least three acceptable flow-volume curves and the second-highest $\mathrm{FEV}_{6}$ and $\mathrm{FEV}_{1}$ were within $0.2 \mathrm{~L}$ or $10 \%$ of highest value). We selected the best value for the report.

\section{Spirometry}

Spirometry testing was performed independently by trained operators according to American Thoracic Society/European Respiratory Society guidelines[30]. Operators were blinded to the COPD-6® results. All study sites used the same model spirometer (JAEGER-Master Screen Pneumo®, Carefusion ${ }^{\mathrm{TM}}$, GER). Spirometers were calibrated before each day's testing. Lung function parameters were measured before and $15 \sim 25$ minutes after inhaling a dose of $400 \mu \mathrm{g}$ salbutamol through a $500 \mathrm{ml} \mathrm{spacer}$. We determined a quality grade $(\mathrm{A} \sim \mathrm{F})$ based on acceptable maneuvers and repeatability of the $\mathrm{FEV}_{1}$ and $\mathrm{FVC}[31]$. Spirometry results with grades $\mathrm{A}, \mathrm{B}$, or $\mathrm{C}$ were considered acceptable for analysis.

\section{Definitions and diagnostic criteria of COPD}

Conventional spirometry results were classified as COPD if the post-bronchodilation $\mathrm{FEV}_{1} / \mathrm{FVC}$ ratio was $<0.7$. COPD was classified as stage I ( $\mathrm{FEV}_{1}>80 \%$ of predicted value), stage II ( $50 \% \leq \mathrm{FEV}_{1}<80 \%$ of predicted value), stage III ( $30 \% \leq \mathrm{FEV}_{1}<50 \%$ of predicted value), and stage IV ( $\mathrm{FEV}_{1}<30 \%$ of predicted value). 


\section{Analysis}

Standard validation measures, including sensitivity, specificity, positive predictive value (PPV), negative predictive value (NPV), and likelihood ratio (for a positive test, $L R+$ ) were calculated at different cut-off points of $\mathrm{FEV}_{1} / \mathrm{FEV}_{6}$. ROC curve will be used to facilitate the cut-off point. The correlations of $\mathrm{FEV}_{1}, \mathrm{FEV}_{6}$, $\mathrm{FEV}_{1} / \mathrm{FEV}_{6}$ measured by the COPD-6® (pre-bronchodilator), with FEV FVC, FEV $_{1} / \mathrm{FVC}$ measured by spirometry (post-bronchodilator), were examined by Pearson's correlation analysis and Bland-Altman plots $^{28}$. The $95 \%$ confidence interval was presented for all variables.

Our study protocol was approved by the Medical Ethics Committee of the Guangzhou Institute of Respiratory Diseases. Analysis was performed in SPSS (version 24).

\section{Results}

1,650 subjects were initially recruited ( 978 from urban region, 672 from the rural county). We excluded 120 subjects because of missing data, and 43 subjects whose quality results of spirometry were under grade $\mathrm{C}$. Information about symptoms was available from 1486 subjects. There were 845 (56.9\%) neversmokers and 641 (43.1\%) smokers in our study. The prevalence of COPD was different among diverse smoking status and respiratory symptoms population (Table 1). 1258 (84.7\%) subjects with $\mathrm{FEV}_{1} / \mathrm{FVC} \geq$ 70\%, 229 (15.4\%) were diagnosed COPD ( $\left.\mathrm{FEV}_{1} / \mathrm{FVC}<70 \%\right) .105$ COPD patients (45.9\%) were GOLD stage I, $91(39.7 \%)$ were GOLD stage II, 28(12.2\%) were GOLD stage III, and 5(6.3\%) were GOLD stage IV. 
Table 1

Characteristics of all participants

\begin{tabular}{|c|c|c|}
\hline & Non-COPD $(\mathrm{N}=1258)$ & COPD $(N=229)$ \\
\hline \multicolumn{3}{|l|}{ Area } \\
\hline Urban & 945 & 121 \\
\hline Rural & 542 & 108 \\
\hline \multicolumn{3}{|l|}{ Sex } \\
\hline men & 877 & 188 \\
\hline women & 610 & 41 \\
\hline \multicolumn{3}{|l|}{ Age (years) } \\
\hline $40 \sim 49$ & 222 & 7 \\
\hline $50 \sim 59$ & 641 & 73 \\
\hline $60 \sim 69$ & 464 & 92 \\
\hline$\geq 70$ & 160 & 57 \\
\hline \multicolumn{3}{|l|}{$\mathrm{BMI}\left(\mathrm{kg} / \mathrm{m}^{2}\right)$} \\
\hline$<18.5$ & 116 & 32 \\
\hline $18.5 \sim 23.9$ & 782 & 129 \\
\hline $24.0 \sim 27.9$ & 460 & 57 \\
\hline$\geq 28.0$ & 129 & 11 \\
\hline \multicolumn{3}{|l|}{ Smoking status } \\
\hline Never-smoker & 845 & 70 \\
\hline Smoker & 641 & 159 \\
\hline \multicolumn{3}{|l|}{ Respiratory symptoms } \\
\hline With respiratory symptom & 362 & 111 \\
\hline Without respiratory symptom & 1124 & 117 \\
\hline \multicolumn{3}{|l|}{ Lung function } \\
\hline FEV1/FVC $>0.7$ & 1258 & - \\
\hline GOLD stage I & - & 105 \\
\hline GOLD stage II & - & 91 \\
\hline
\end{tabular}




\begin{tabular}{|lll|}
\hline & Non-COPD $(\mathbf{N}=1258)$ & COPD $(\mathbf{N}=229)$ \\
\hline GOLD stage III & - & 28 \\
\hline GOLD stage IV & - & 5 \\
\hline
\end{tabular}

Figure $1(\mathrm{~A})$ shows the strong correlation between $\mathrm{FEV}_{1}$ measured by two machines in total population $\left(r_{1}=0.889, P<0.001\right)$, non-COPD group $\left(r_{2}=0.869, P<0.001\right)$ and COPD group $\left(r_{3}=0.907, P<0.001\right)$. Significant difference was observed between non-COPD group and COPD group $(z=2.509, P=0.012)$. Figure 1 (B) shows strong relationships between $\mathrm{FEV}_{1}$ measured by spirometry and COPD-6® in groups of GOLD stage I $\left(r_{\mid}=0.810, P<0.001\right)$, stage II $\left(r_{I_{I}}=0.802, P<0.001\right)$ and stage III $\left(r_{I_{I I}}=0.637, P<0.001\right)$ but nonsignificant correlation was found in GOLD stage IV group $\left(r_{I V}=0.844, P=0.072\right)$. No statistical significance was found among GOLD stage I, stage II and stage III ( $r_{\mid} v s . r_{\| l}: z=0.141, P=0.887 ; r_{1} v s . r_{\| I}: z$ $\left.=1.675, \mathrm{P}=0.094 ; r_{\| \mid} v s . r_{|| l}: z=1.558, P=0.119\right)$. Bland-Altman graph of $F V_{1}$ measured by spirometry and COPD-6 $\AA$ is shown in Fig. 1 (C). The limit of Agreement (LoA) was $0.445 \sim 0.816 \mathrm{~L}$, and 4.5\% (67/1487) points were out of the $95 \%$ LoA.

Figure 2 (A) shows strong correlations between FVC measured by spirometry with $\mathrm{FEV}_{6}$ measured by COPD-6 ${ }^{\circledR}$ in total population $\left(r_{1}=0.835, P<0.001\right)$, non-COPD group $\left(r_{2}=0.865, P<0.001\right)$ and COPD group $\left(r_{3}=0.807, P<0.001\right)$. Statistical difference was detected between non-COPD group and COPD group $(z=2.668, P=0.008)$. Figure $2(B)$ shows strong relationships between $F V C$ measured by spirometry and $F E V_{6}$ measured by COPD- $6 \AA$ in groups of GOLD stage $I\left(r_{1}=0.737, P<0.001\right)$, stage II $\left(r_{\mid I}=0.724, P<0.001\right)$, stage III $\left(r_{\mid I I}=0.574, P=0.0014\right)$, but no significant correlation was found in GOLD stage IV group $\left(r_{\mid V}=0.615, P=0.269\right)$. No significant difference was found among groups $\left(r_{\mid} v s . r_{\mid l}: z=\right.$ $\left.0.187, \mathrm{P}=0.851 ; r_{1} v s . r_{\| 11}: z=1.301, P=0.193 ; r_{\| 1} v s . r_{\| 11}: z=1.161, P=0.246\right)$. Figure $2(C)$ shows the BlandAltman graph of FVC by spirometry and FEV ${ }_{6}$ by COPD- $6 \AA$. LoA was $0.514 \sim 1.297 \mathrm{~L}$, and $5.2 \%(77 / 1487)$ points were out of the $95 \%$ LoA.

Figure $3\left(\mathrm{~A}\right.$ ) shows the relationship between $\mathrm{FEV}_{1} / \mathrm{FVC}$ measured by spirometry and $\mathrm{FEV}_{1} / \mathrm{FEV}_{6}$ measured by COPD- $6 \AA$ in total group $\left(r_{1}=0.647, P<0.001\right)$, non-COPD group $\left(r_{2}=0.343, P<0.001\right)$ and COPD group $\left(r_{3}=0.686, P<0.001\right)$. Figure $3(B)$ presented the relationship between $F E V_{1} / F V C$ measured by spirometry and FEV $F_{6} / F V C$ measured by COPD- $6 \circledast$ in groups of GOLD stage I $\left(r_{1}=0.197, P<0.044\right)$, stage II $\left(r_{||}=0.641, P<0.001\right)$, stage III $\left(r_{I I I}=0.715, P<0.001\right)$ and stage IV $\left(r_{I V}=0.784, P=0.117\right)$. Figure $3(C)$ is the Bland-Altman graph of FVC by spirometry and FEV 6 by COPD- $6 \AA$ and the $95 \%$ LoA is -20.944 to 12.822.

Table 2 presented the AUC, sensitivity, specificity, positive predictive value (PPV), negative predictive value (NPV) and positive likelihood ratio (LR+) at different cut-off points of $\mathrm{FEV}_{1} / \mathrm{FEV}_{6}$ ratios. The AUC was largest (i.e., 0.80 ) when the cut-off point is 0.77 . 
Table 2

The measures on sensitivity and specificity at different cut-off points of $\mathrm{FEV}_{1} / \mathrm{FEV}_{6}$.

\begin{tabular}{|lllllll|}
\hline Cut-off point & AUC $^{\mathrm{a}}$ & SE\% $^{\mathrm{b}}$ & SP\% $^{\mathrm{c}}$ & PPV\% $^{\mathrm{d}}$ & NPV\% & LR ${ }^{\mathrm{f}}$ \\
\hline$<0.65$ & 0.62 & 25.82 & 98.93 & 80.80 & 88.02 & 23.15 \\
\hline$<0.70$ & 0.70 & 41.95 & 97.92 & 78.75 & 90.34 & 20.28 \\
\hline$<0.75$ & 0.77 & 60.22 & 92.96 & 60.83 & 92.37 & 8.52 \\
\hline$<0.77$ & 0.80 & 69.94 & 89.98 & 55.78 & 94.29 & 6.92 \\
\hline$<0.80$ & 0.79 & 77.78 & 80.13 & 41.63 & 95.24 & 3.91 \\
\hline & \\
\hline & \\
\hline &
\end{tabular}

ROC curve was used to determine the best corresponding cut-off for $\mathrm{FEV}_{1} / \mathrm{FEV}_{6}$ (Fig. 4A). When the $\mathrm{FEV}_{1} / \mathrm{FEV}_{6}$ cut-off value of was 0.77 , the area under the receiver operator characteristic curve (AUC) was 0.86 (95\% Cl: $0.83-0.89)$ and the sensitivity (71.2\%) and specificity (89.8\%) was greatest. Table 2 shows AUC, sensitivity, specificity, positive predictive value (PPV), negative predictive value (NPV) and positive likelihood ratio (LR+) at different cut-off points of $\mathrm{FEV}_{1} / \mathrm{FEV}_{6}$ ratios.

Figure $4(\mathrm{~B})$ shows ROC curves of $\mathrm{FEV}_{1} / \mathrm{FEV}_{6}$ measured by $\mathrm{COPD}-6{ }^{\circledR}$ to identify airflow obstruction in the symptoms group and asymptomatic patients. AUC were 0.87 (95\% Cl: $0.82-0.916)$ and $0.84(95 \% \mathrm{Cl}$ : $0.802-0.884)$, no significant difference $(z=0.789, P=0.425)$ was observed between two groups. The AUC of $\mathrm{FEV}_{1} / \mathrm{FEV}_{6}$ that used to identify airflow obstruction in the smoker group (including current smokers and ex-smokers) and the never-smokers were 0.86 (95\% Cl: 0.82 to 0.90$)$ and 0.84 (95\% Cl: 0.79 to 0.89 ), respectively. No significant difference was observed $(z=0.651, P=0.515)$ (Fig. 4C).

\section{Discussion}

This is the first study to confirm the validity of a handheld expiratory device (COPD-6®) for COPD screening for primary care settings in China. We also came out with result that the appropriate cut-off 
value for $\mathrm{FEV}_{1} / \mathrm{FEV}_{6}$ to determine airflow limitation was 0.77 in Chinese primary care settings, including both rural and urban area.

It has already been demonstrated that $\mathrm{FEV}_{6}$ is a reliable alternative for $\mathrm{FVC}$ to detect airway obstruction and restriction[20]. There are two types of handheld tools for measuring $\mathrm{FEV}_{6}$ and $\mathrm{FEV}_{1} / \mathrm{FEV}_{6}$ : the Piko-6 (Ferraris Co., UK) and the COPD-6® (Vitalograph Ltd., Ireland). Previous studies have demonstrated that these devices could be useful in detecting pulmonary obstructive pathologies[23-28, 32]. However, the best cut off point to use for defining airflow obstruction remained uncertain. Vandevoorde et al. [33] and Melbye et al.[34] reported that $\mathrm{FEV}_{1} / \mathrm{FEV}_{6}<70-73 \%$ can be used as a valid alternative to $\mathrm{FEV}_{1} / \mathrm{FVC}<70 \%$ for the detection of obstruction using conventional spirometers. Rosa et al. reported that the best cut-off point for the $\mathrm{FEV}_{1} / \mathrm{FEV}_{6}$ ratio was 0.75 in subjects aged 40 years or over[35]. However, these studies were performed with conventional spirometers. Since we used the COPD-6®, a handheld spirometer, we cannot blindly adapt these values to our study directly.

In our study, we use $\mathrm{FEV}_{1} / \mathrm{FVC}<70 \%$ as the "gold standard" to detect airflow obstruction. The AUC for $\mathrm{FEV}_{1} / \mathrm{FEV}_{6}$ to identify airflow limitation was 0.857 . The best cut-off point for $\mathrm{FEV}_{1} / \mathrm{FEV}_{6}$ was $77.15 \%$ with a sensitivity of $71.2 \%$ and specificity of $89.8 \%$. Besides, almost all of the discordant cases were close to the cut-off value. Our results in line with previous study which determined $73 \%$ as the cut-off value with greatest sensitivity and specificity[27]. The latest study from United Kingdom also support our result with closely cutoff (e.g., 78\%)[36].

There are several seasons lead to the heterogeneity of studies: methodological measures, different prevalence of airway limitation and the cut off points used to define airflow obstruction. Previous results of multiple meta-regression presented that the prevalence of airway limitation may have an effect on diagnostic-odds ratio[21]. According to previous study, sensitivity and specificity was dependent on the prevalence of moderate-to-severe airway obstruction. Low prevalence of severe airway obstruction may reduce the sensitivity of $\mathrm{FEV}_{6}$, and Low prevalence of mild airway obstruction reduced the specificity of $\mathrm{FEV}_{6}$ [37]. In our study, subjects were randomly selected and representative of the real world. Subjects included smokers and non-smokers, rural and urban residents, previous diagnosed and never diagnosed COPD patients. In this study, the prevalence of obstruction was $15.3 \%(229 / 1487)$. The best cut-off point for $\mathrm{FEV}_{1} / \mathrm{FEV}_{6}$ was $77.15 \%$ with a sensitivity of $71.2 \%$ and specificity of $89.8 \%$. In previous study, (population aged 45-85 years and with smoking history of $>15$ pack-years), sensitivity and specificity were $79.2 \%$ and $80.3 \%$ when cut-off value was set as $73 \%$ [27]. Despite the inconstant result of cut-off point of $F E V_{1} / \mathrm{FEV}_{6}$, our findings show that $\mathrm{COPD}-6 \AA$ device was effective in detecting previously undiagnosed COPD and ought to be used as a tool for COPD screening in Chinese primary care settings. We came out with a result that about one of two patients whose $\mathrm{FEV}_{1} / \mathrm{FEV}_{6}<0.77$ will exhibit airflow limitation with spirometry.

Furthermore, similar AUC values were obtained in the symptomatic population (AUC $=0.87$ ) and asymptomatic population $(A \cup C=0.84)$. No significant difference was observed between smoking group 
(including smokers and ex-smokers) $(A U C=0.86)$ and non-smokers $(A U C=0.84)$. The results remind us that the COPD-6® device was effective in detecting airflow limitation for population with diverse characteristics, especially in non-smokers and asymptomatic patients.

To our best knowledge, handheld spirometric measurements (i.e., COPD-6®) are not identical to conventional spirometry. The most limitation of this approach was handheld spirometric measurements may not be appropriate to be used for determining the grade of airflow limitation. We assessed the correlation of several measures by COPD- $6 \AA$ and spirometry in different stages of COPD. No significant correlations were observed between $\mathrm{FVC}$ measured by spirometry and $\mathrm{FEV}_{6}$ measured by COPD-6® in GOLD stage IV. FEV $1 / F V C$ measured by spirometry was also not correlated with $\mathrm{FEV}_{1} / \mathrm{FEV}_{6}$ measured by COPD-6® in GOLD stage IV.

These phenomena indicated the fact that COPD- $6 \AA$ may not be appropriate to be used for determining the grade of airflow limitation.

There are several potential reasons for differences and inconsistency mentioned above: (1) FEV $1 / F V C$ and FVC are more dependent on the FET(Forced expiratory time) than $\mathrm{FEV}_{1} / \mathrm{FEV}_{6}$ and $\mathrm{FEV}_{6}$ [38]; (2) Instead of measuring the whole FVC, COPD- $6 \circledR$ testing stops measuring after $6 \mathrm{~s}$ and results in the risk of overstating $\mathrm{FEV}_{1} / \mathrm{FEV}_{6}$ ratio; (3) $\mathrm{COPD}-6 \AA$ does not provide graph analysis of the volume/time or flow/volume curves that are essential (especially the later ones) in quality control; (4)In this study, COPD$6 \circledast$ were performed before the use of bronchodilation, and the conventional spirometry were adapted after the process of post-bronchodilation; (5) In our study, only five patients were GOLD stage IV, which might cause statistical bias.

However, limitations mentioned above is irrelevant for the COPD screening in primary care settings. Utilization of handheld expiratory flow meter (COPD-6®) was aimed to reduce misdiagnosis rate and avoid the waste of medical resources at the same time. Our study, including the handheld expiratory flow meter and its cutoff value, can be widely recommended for the practice of COPD screening in Chinese communities.

\section{Conclusions}

The handheld Vitalograph COPD-6® meter could be used as a pre-screening device in early diagnosis of COPD in Chinese primary care settings. Furthermore, it should be noted that the cut-off value for $\mathrm{FEV}_{1} / \mathrm{FEV}_{6}$ to determine airflow limitation was 0.77 .

\section{List Of Abbreviations}

COPD, chronic obstructive pulmonary disease; $\mathrm{FEV}_{1}$, forced expiratory volume in one second; $\mathrm{FEV}_{6}$, forced expiratory volume in six seconds; FVC, forced vital capacity; AUC, area under the receiver operator characteristic curve; GOLD, global initiative for chronic obstructive lung disease; LoA, limit of Agreement. 


\section{Declarations}

Ethics approval and Consent to participate

Not applicable.

Consent for publication

Not applicable.

Availability of data and materials

All data which were generated or analysed are included in this published article and also its supplementary information files.

Competing interests

The authors declare that they have no competing interests.

\section{Funding}

This study was supported by the National Key R\&D Program of China, Ministry of Science and Technology of China (2016YFC1304100), the National Natural Science Foundation of China (81970045, 81570035), the special fund for preventing and controlling the COVID-19, Guangdong, China (2020B1111330001), and Provincial Innovation and Research Team Project of Guangdong Pearl River Talents Program, China (2017BT01S155). However, study funding mentioned above had no influence on the process of study. There was no conflict of interest for all authors.

\section{Authors' contributions}

Pixin Ran, Shuyun Chen, Yumin Zhou, Xiaochen Li and Zihui Wang designed the study. Shuyun Chen and Xiaochen Li participated in data organization. Shuyun Chen and Zihui Wang participated in data analysis. Shuyun Chen, Yumin Zhou, and Zihui Wang contributed to interpretation of the findings. Shuyun Chen and Zihui Wang drafted the manuscript. Yumin Zhou and Zihui Wang contributed to article modification. Other authors participated in data collection. All authors have contributed to the last version of the manuscript. The authors read and approved the final manuscript.

Acknowledgements

Not applicable.

\section{References}

1. Mathers, Loncar: Projections of global mortality and burden of disease from 2002 to 2030. PLoS Med 2006, 3:e442. 
2. World Health Organisation: The Global Burden of disease: 2004 update.2008.

3. Collaborators: Global, regional, and national deaths, prevalence, disability-adjusted life years, and years lived with disability for chronic obstructive pulmonary disease and asthma, 1990-2015: a systematic analysis for the Global Burden of Disease Study 2015. Lancet Respir Med 2017, 5:691706.

4. Lange, Halpin, O'Donnell, MacNee: Diagnosis, assessment, and phenotyping of COPD: beyond FEV(1). Int J Chron Obstruct Pulmon Dis 2016, 11 Spec Iss:3-12 \%! Diagnosis, assessment, and phenotyping of COPD: beyond FEV(11).

5. Global Strategy for the Diagnosis, Management, and Prevention of Chronic Obstructive Lung Disease: The GOLD Science Committee Report 2019. European Respiratory Journal 2019.

6. Celli, MacNee: Standards for the diagnosis and treatment of patients with COPD: a summary of the ATS/ERS position paper. Eur Respir J 2004, 23:932-946.

7. Soriano, Zielinski, Price: Screening for and early detection of chronic obstructive pulmonary disease. Lancet 2009, 374:721-732.

8. Freeman, Price: ABC of chronic obstructive pulmonary disease. Primary care and palliative care. BMJ 2006, 333:188-190.

9. Bednarek, Maciejewski, Wozniak, Kuca, Zielinski: Prevalence, severity and underdiagnosis of COPD in the primary care setting. Thorax 2008, 63:402-407.

10. Labonté, Tan, Li, Mancino, Aaron, Benedetti, et al: Undiagnosed Chronic Obstructive Pulmonary Disease Contributes to the Burden of Health Care Use. Data from the CanCOLD Study. Am J Respir Crit Care Med 2016, 194:285-298y.

11. Han, Kim, Mardon, Renner, Sullivan, Diette, et al: Spirometry utilization for COPD: how do we measure up? Chest 2007, 132:403-409

12. Johns, Burton, Walters, Wood-Baker: National survey of spirometer ownership and usage in general practice in Australia. Respirology 2006, 11:292-298.

13. Leuppi, Miedinger, Chhajed, Buess, Schafroth, Bucher, et al: Quality of spirometry in primary care for case finding of airway obstruction in smokers. Respiration 2010, 79:469-474.

14. Derom, van Weel, Liistro, Buffels, Schermer, Lammers, et al: Primary care spirometry. Eur Respir J 2008, 31:197-203.

15. Qaseem, Snow, Shekelle, Sherif, Wilt, Weinberger, et al: Diagnosis and management of stable chronic obstructive pulmonary disease: a clinical practice guideline from the American College of Physicians. Ann Intern Med 2007, 147:633-638.

16. Screening for chronic obstructive pulmonary disease using spirometry: U.S. Preventive Services Task Force recommendation statement. Ann Intern Med 2008, 148:529-534.

17. Prats, Tejero, Pardo, Gavilán, Galera, Donado, et al: Prognostic Value of the Six-Second Spirometry in Patients with Chronic Obstructive Pulmonary Disease: A Cohort Study. PLoS One 2015, 10:e0140855. 
18. Chung, Jung, Park, Kim, Kim, Chang, et al: Cut-off value of FEV1/FEV6 as a surrogate for FEV1/FVC for detecting airway obstruction in a Korean population. Int J Chron Obstruct Pulmon Dis 2016, 11:1957-1963.

19. Lundgren, Cabral, Climaco, de Macedo, Coelho, Dias: Determination of the efficacy of FEV6 as a surrogate for FVC in the diagnostic screening for chronic obstructive pulmonary disease through the comparison of FEV1/FVC and FEV1/FEV6 ratios. J Bras Pneumol 2007, 33:148-151.

20. Vandevoorde, Verbanck, Schuermans, Kartounian, Vincken: FEV1/FEV6 and FEV6 as an alternative for FEV1/FVC and FVC in the spirometric detection of airway obstruction and restriction. Chest 2005, 127:1560-1564.

21. Vollmer, Gislason, Burney, Enright, Gulsvik, Kocabas, et al: Comparison of spirometry criteria for the diagnosis of COPD: results from the BOLD study. Eur Respir J 2009, 34:588-597.

22. Jing, Huang, Cui, Xu, Shen: Should FEV1/FEV6 replace FEV1/FVC ratio to detect airway obstruction? A metaanalysis. Chest 2009, 135:991-998.

23. Frith, Crockett, Beilby, Marshall, Attewell, Ratnanesan, et al: Simplified COPD screening: validation of the PiKo-6(R) in primary care. Prim Care Respir J 2011, 20:190-198.

24. Sichletidis, Spyratos, Papaioannou, Chloros, Tsiotsios, Tsagaraki, et al: A combination of the IPAG questionnaire and PiKo-6(R) flow meter is a valuable screening tool for COPD in the primary care setting. Prim Care Respir J 2011, 20:184-189.

25. Wada, Nakano, Nagao, Osawa, Yamada, Sakaguchi, et al: Detection and prevalence of chronic obstructive pulmonary disease in a cardiovascular clinic: evaluation using a hand held FEV/FEV meter and questionnaire. Respirology 2010, 15:1252-1258.

26. Represas, Botana, Leiro, Gonzalez, Del, Fernandez-Villar: [Assessment of the portable COPD-6 device for detecting obstructive airway diseases]. Arch Bronconeumol 2010, 46:426-432.

27. Thorn, Tilling, Lisspers, Jorgensen, Stenling, Stratelis: Improved prediction of COPD in at-risk patients using lung function pre-screening in primary care: a real-life study and cost-effectiveness analysis. Prim Care Respir J 2012.

28. Miravitlles, Llor, Calvo, Diaz, Diaz-Cuervo, Gonzalez-Rojas: [Validation of the Spanish version of the Chronic Obstructive Pulmonary Disease-Population Screener (COPD-PS). Its usefulness and that of FEV(1)/FEV(6) for the diagnosis of COPD.]. Med Clin (Barc) 2011.

29. Nishimura, Nakayasu, Kobayashi, Mitsuma: Case identification of subjects with airflow limitations using the handheld spirometer "Hi-Checker" : comparison against an electronic desktop spirometer. COPD 2011, 8:450-455.

30. Miller, Hankinson, Brusasco, Burgos, Casaburi, Coates, et al: Standardisation of spirometry. Eur Respir J 2005, 26:319-338.

31. Enright PI: Spirometry to detect and manage chronic obstructive pulmonary disease and asthma in the primary care setting. In Lung function testing. Edited by Wouters Ef GRSH: Eur Respir Mon; 2005: $1 \sim 14$. 
32. Toda, Hoshino, Kawayama, Imaoka, Sakazaki, Tsuda, et al: Validation of "lung age" measured by spirometry and handy electronic FEV1/FEV6 meter in pulmonary diseases. Intern Med 2009, 48:513521.

33. Vandevoorde, Verbanck, Schuermans, Kartounian, Vincken: Obstructive and restrictive spirometric patterns: fixed cut-offs for FEV1/FEV6 and FEV6. Eur Respir J 2006, 27:378-383.

34. Melbye, Medbo, Crockett: The FEV1/FEV6 ratio is a good substitute for the FEV1/FVC ratio in the elderly. Prim Care Respir J 2006, 15:294-298.

35. Rosa, Perez-Padilla, Camelier, Nascimento, Menezes, Jardim: Efficacy of the FEV1/FEV6 ratio compared to the FEV1/FVC ratio for the diagnosis of airway obstruction in subjects aged 40 years or over. Braz J Med Biol Res 2007, 40:1615-1621.

36. Dickens, Fitzmaurice, Adab, Sitch, Riley, Enocson, et al: Accuracy of Vitalograph lung monitor as a screening test for COPD in primary care. NPJ Prim Care Respir Med 2020, 30:2.

37. Lamprecht, Schirnhofer, Tiefenbacher, Kaiser, Buist, Studnicka, et al: Six-second spirometry for detection of airway obstruction: a population-based study in Austria. Am J Respir Crit Care Med 2007, 176:460-4.

38. Perez-Padilla, Wehrmeister, Celli, Lopez-Varela, Montes, Muino, et al: Reliability of FEV1/FEV6 to diagnose airflow obstruction compared with FEV1/FVC: the PLATINO longitudinal study. PLoS One 2013, 8:e67960.

\section{Figures}
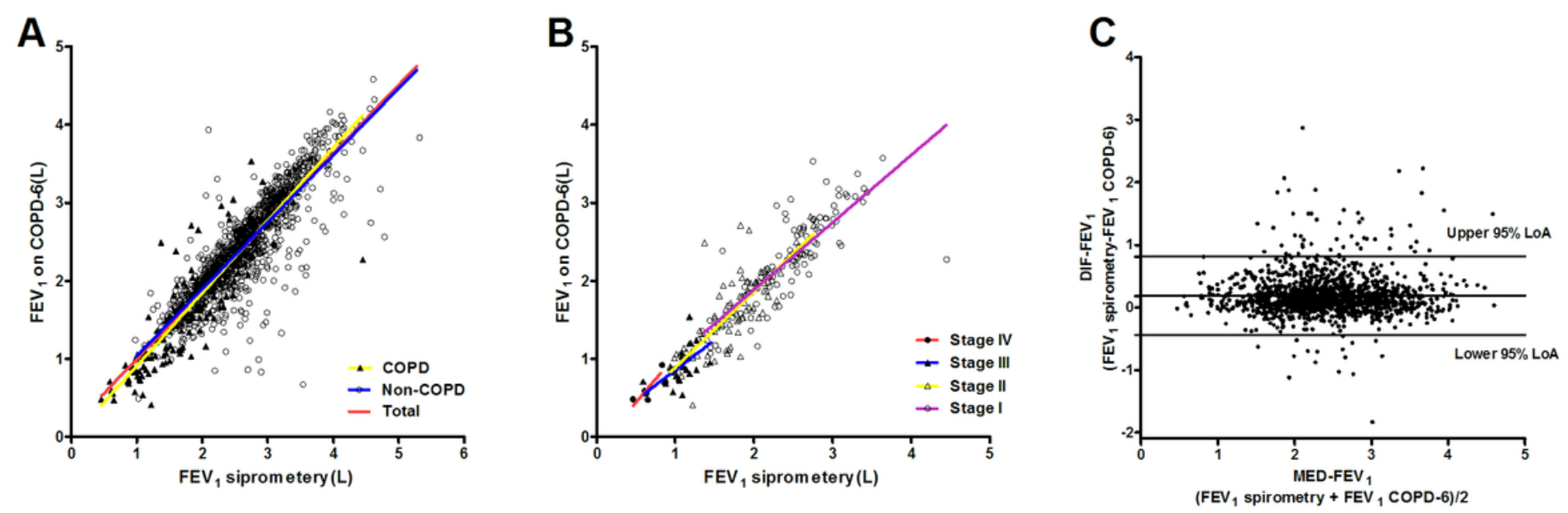

Figure 1

Correlation of FEV1 measured by spirometry with FEV1 measured by COPD-6 (A) Relationship between FEV1 measured by spirometry and FEV1 measured by COPD- $6 \AA$ in total group $(r 1=0.889, P<0.001)$, nonCOPD group $(r 2=0.869, P<0.001)$ and COPD group $(r 3=0.907, P<0.001)$. (B) Relationship between FEV1 measured by spirometry and COPD- $6 \AA$ in the groups of GOLD stage I $(r l=0.810, P<0.001)$, stage II 
( $\mathrm{rll}=0.802, \mathrm{P}<0.001)$, stage III ( $\mathrm{rllI}=0.637, \mathrm{P}<0.001)$ and stage IV (rIV=0.844,P<0.001). (C) Bland-Altman graph of FEV1 measured by spirometry and COPD-6®. 4.5\% (67/1487) plots were out of the 95\%LoA(-0.445 0.816L).
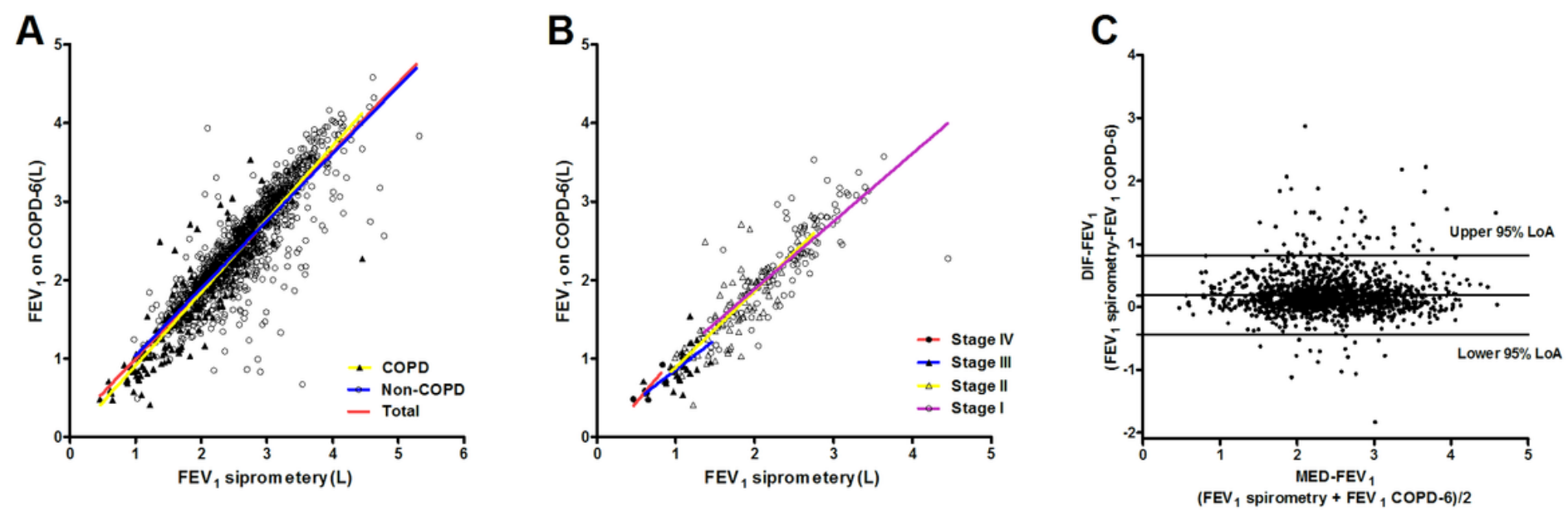

Figure 1

Correlation of FEV1 measured by spirometry with FEV1 measured by COPD-6 (A) Relationship between FEV1 measured by spirometry and FEV1 measured by COPD-6® in total group $(r 1=0.889, P<0.001)$, nonCOPD group ( $\mathrm{r} 2=0.869, \mathrm{P}<0.001$ ) and COPD group ( $\mathrm{r} 3=0.907, \mathrm{P}<0.001)$. (B) Relationship between FEV1 measured by spirometry and COPD- $6 \AA$ in the groups of GOLD stage I $(r l=0.810, P<0.001)$, stage II ( $\mathrm{rll}=0.802, \mathrm{P}<0.001)$, stage III ( $\mathrm{rll}=0.637, \mathrm{P}<0.001)$ and stage IV ( $\mathrm{rlV}=0.844, \mathrm{P}<0.001)$. (C) Bland-Altman graph of FEV1 measured by spirometry and COPD-6®. 4.5\% (67/1487) plots were out of the 95\%LoA(-0.445 0.816L).
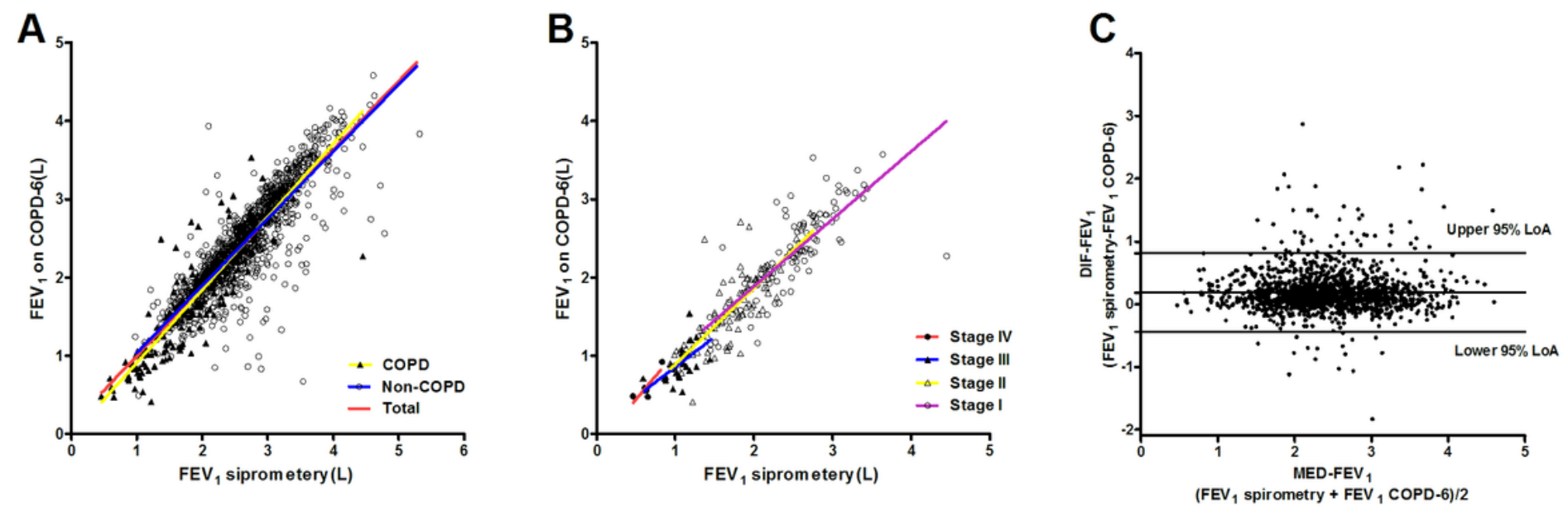

Figure 1

Correlation of FEV1 measured by spirometry with FEV1 measured by COPD-6 (A) Relationship between FEV1 measured by spirometry and FEV1 measured by COPD-6 $®$ in total group $(r 1=0.889, P<0.001)$, nonCOPD group ( $\mathrm{r} 2=0.869, \mathrm{P}<0.001)$ and COPD group ( $\mathrm{r} 3=0.907, \mathrm{P}<0.001)$. (B) Relationship between FEV1 
measured by spirometry and COPD-6® in the groups of GOLD stage I $(\mathrm{rl}=0.810, \mathrm{P}<0.001)$, stage II ( $\mathrm{rll}=0.802, \mathrm{P}<0.001)$, stage III ( $\mathrm{rll}=0.637, \mathrm{P}<0.001)$ and stage IV ( $\mathrm{rlV}=0.844, \mathrm{P}<0.001)$. (C) Bland-Altman graph of FEV1 measured by spirometry and COPD-6®. 4.5\% (67/1487) plots were out of the 95\%LoA(-0.445 0.816L).
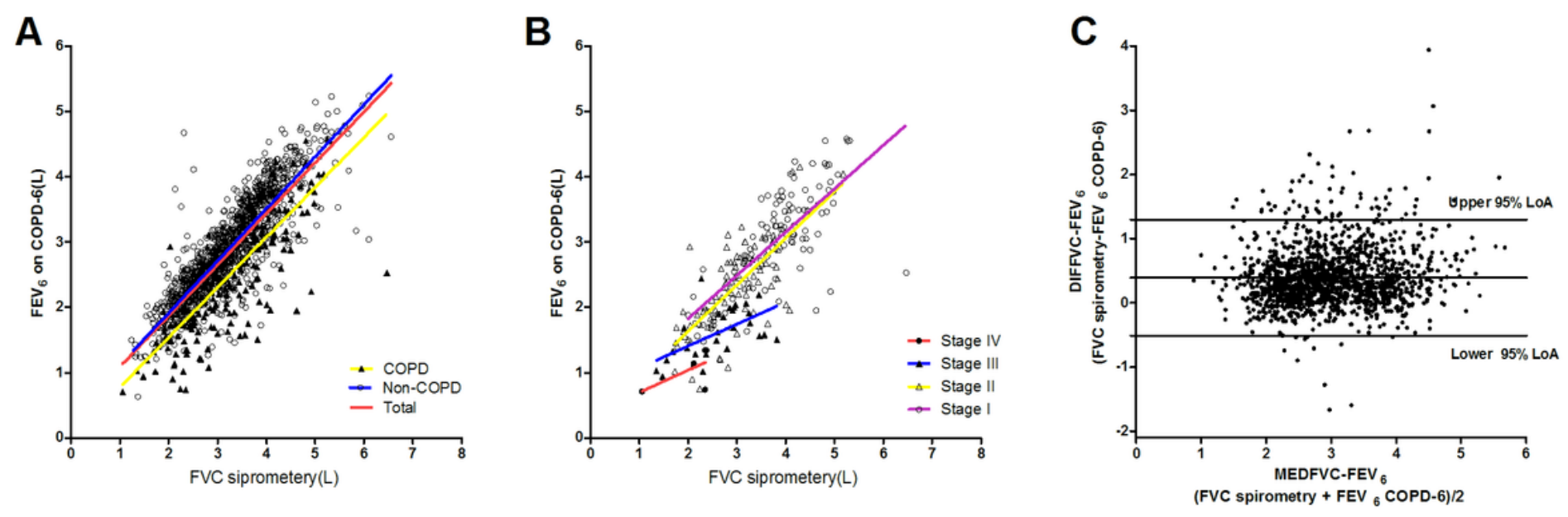

Figure 2

Correlation of FVC measured by spirometry with FEV6 measured by COPD-6 (A)Relationship between FVC measured by spirometry and FEV 6 measured by COPD- $6 \AA$ in total group $(r 1=0.835, P<0.001)$, non-COPD group $(r 2=0.865, P<0.001)$ and COPD group $(r 3=0.807, P<0.001)$. (B) Relationship between FVC measured by spirometry and FEV6 measured by COPD- $6 \AA$ in groups of GOLD stage I $(r l=0.737, P<0.001)$, stage II ( $r l l=0.724, P<0.001)$, stage III ( $r \mid l l=0.574, P=0.0014)$ and stage IV ( $r I V=0.615, P=0.269)$. (C) Bland-Altman graph of FVC by spirometry and FEV6 by COPD-6®. $5.2 \%$ (77/1487) plots were out of the 95\%LoA(0.514 1.297L).
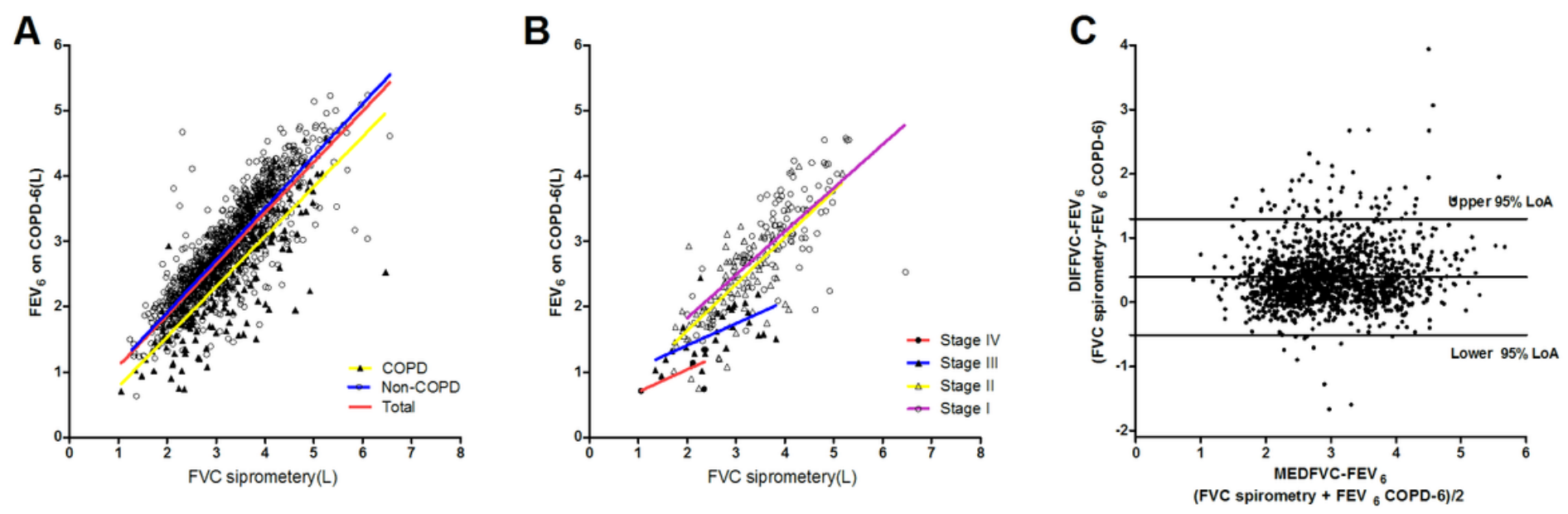

Figure 2

Correlation of FVC measured by spirometry with FEV6 measured by COPD-6 (A)Relationship between FVC measured by spirometry and FEV6 measured by COPD-6 ${ }^{\circledR}$ in total group $(r 1=0.835, P<0.001)$, non-COPD 
group $(r 2=0.865, P<0.001)$ and COPD group $(r 3=0.807, P<0.001)$. (B) Relationship between FVC measured by spirometry and FEV6 measured by COPD- $6 \AA$ in groups of GOLD stage I $(r l=0.737, P<0.001)$, stage II ( $\mathrm{IIl}=0.724, \mathrm{P}<0.001)$, stage III ( $\mathrm{rll}=0.574, \mathrm{P}=0.0014)$ and stage IV ( $\mathrm{rlV}=0.615, \mathrm{P}=0.269)$. (C) Bland-Altman graph of FVC by spirometry and FEV6 by COPD-6®. $5.2 \%$ (77/1487) plots were out of the 95\%LoA(0.514 1.297L).
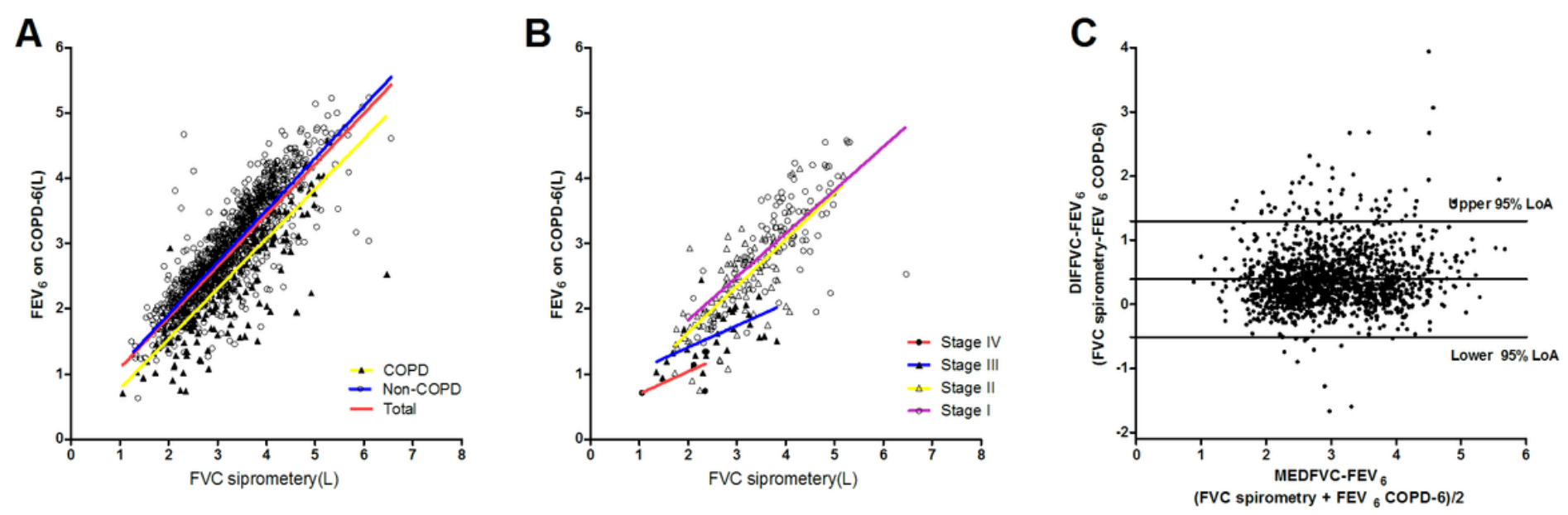

Figure 2

Correlation of FVC measured by spirometry with FEV6 measured by COPD-6 (A)Relationship between FVC measured by spirometry and FEV6 measured by COPD- $6 \AA$ in total group $(r 1=0.835, P<0.001)$, non-COPD group $(r 2=0.865, P<0.001)$ and COPD group $(r 3=0.807, P<0.001)$. (B) Relationship between FVC measured by spirometry and FEV6 measured by COPD- $6 \AA$ in groups of GOLD stage I $(r l=0.737, P<0.001)$, stage II ( $r l l=0.724, P<0.001)$, stage III ( $r l l=0.574, P=0.0014)$ and stage IV ( $r I V=0.615, P=0.269)$. (C) Bland-Altman graph of FVC by spirometry and FEV6 by COPD-6®. 5.2\% (77/1487) plots were out of the 95\%LoA(0.514 1.297L).

A

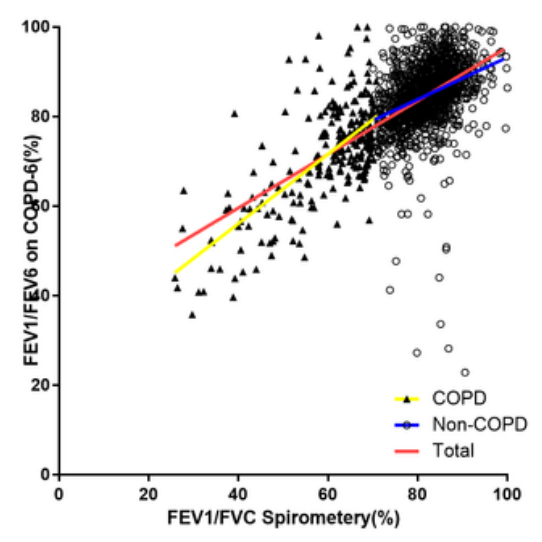

B

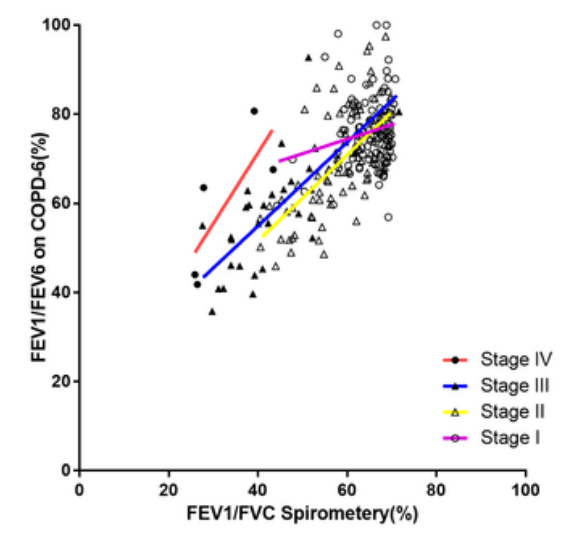

C

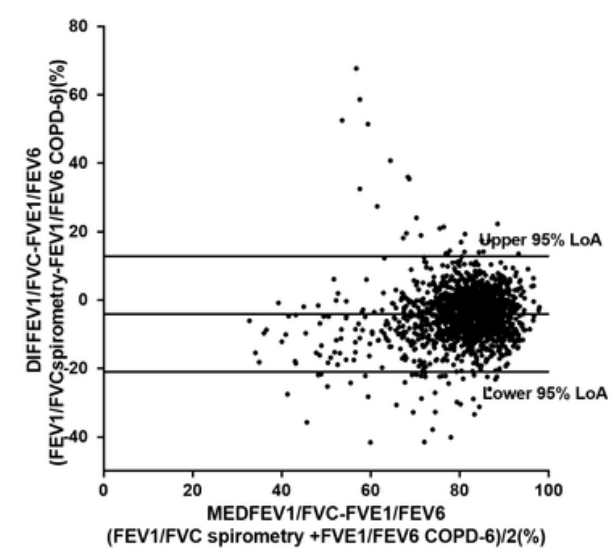

Figure 3 
Correlation of FEV1/FVC measured by spirometry with FEV1/FEV6 measured by COPD-6 (A)Relationship between FEV1/FVC measured by spirometry and FEV1/FEV6 measured by COPD-6® in total group $(r 1=0.647, P<0.001)$, non-COPD group $(r 2=0.343, P<0.001)$ and COPD group $(r 3=0.686, P<0.001)$. (B) Relationship between FEV1/FVC measured by spirometry and FEV6/FVC measured by COPD-6® in groups of GOLD stage I $(r l=0.197, P<0.044)$, stage II $(r l l=0.641, P<0.001)$, stage $I I I(r l l=0.715, P<0.001)$ and stage IV (rIV=0.784, P=0.117). (C) Bland-Altman graph of FVC by spirometry and FEV6 by COPD-6®.

A

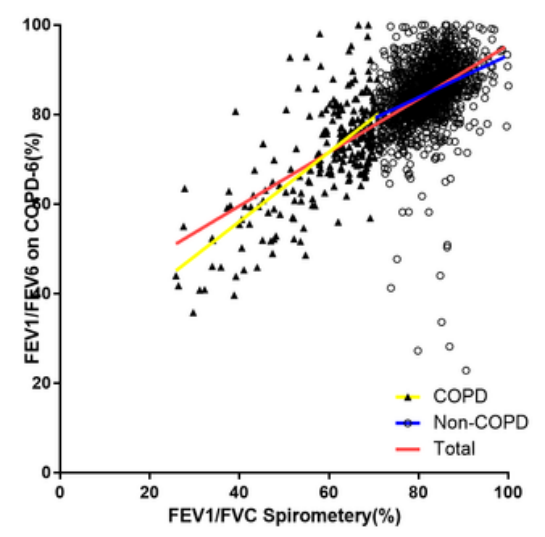

B

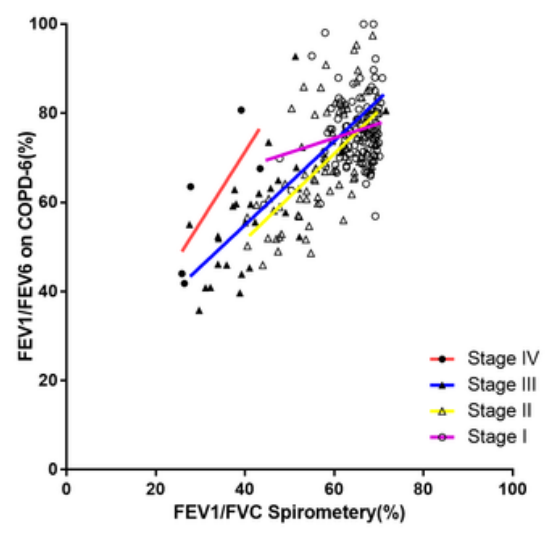

C

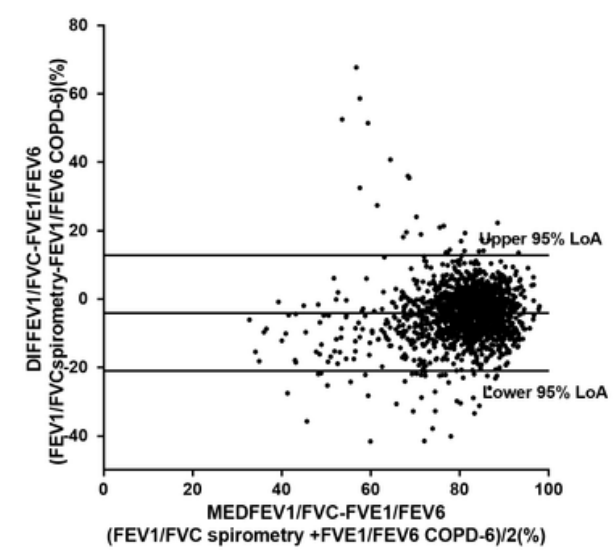

Figure 3

Correlation of FEV1/FVC measured by spirometry with FEV1/FEV6 measured by COPD-6 (A)Relationship between FEV1/FVC measured by spirometry and FEV1/FEV6 measured by COPD-6® in total group $(r 1=0.647, P<0.001)$, non-COPD group ( $r 2=0.343, P<0.001)$ and COPD group $(r 3=0.686, P<0.001)$. $(B)$ Relationship between FEV1/FVC measured by spirometry and FEV6/FVC measured by COPD-6® in groups of GOLD stage I $(r l=0.197, P<0.044)$, stage II $(r l=0.641, P<0.001)$, stage III $(r l l=0.715, P<0.001)$ and stage IV (rIV=0.784, $P=0.117)$. (C) Bland-Altman graph of FVC by spirometry and FEV6 by COPD-6®.

A

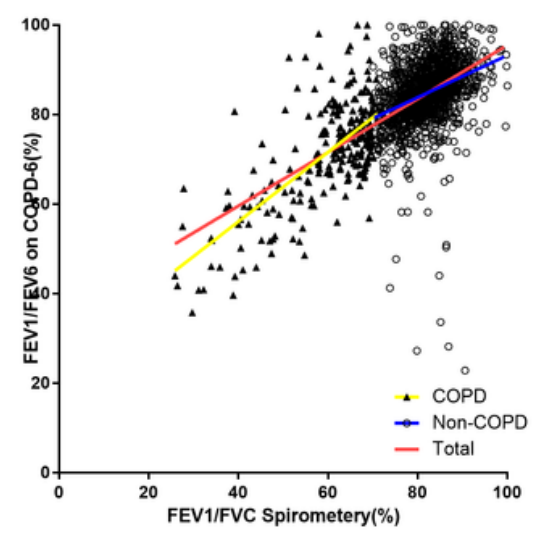

B

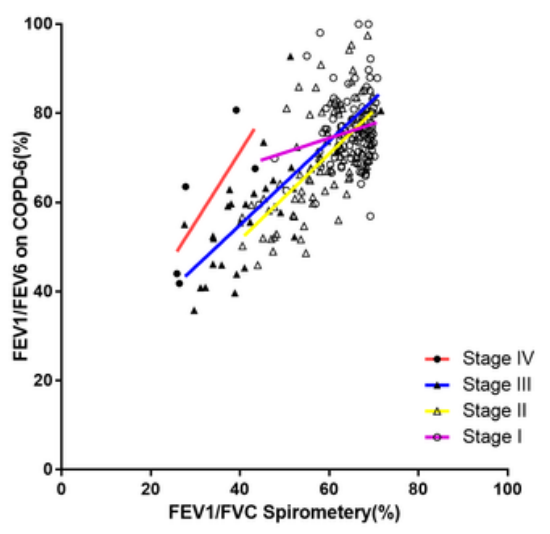

C

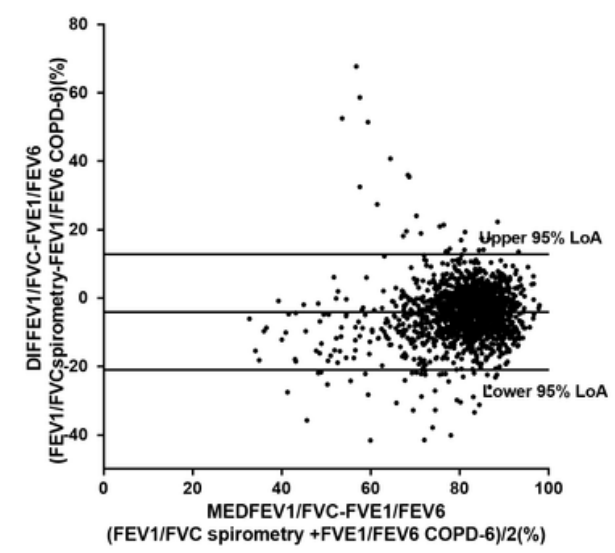

Figure 3 
Correlation of FEV1/FVC measured by spirometry with FEV1/FEV6 measured by COPD-6 (A)Relationship between FEV1/FVC measured by spirometry and FEV1/FEV6 measured by COPD-6® in total group $(r 1=0.647, P<0.001)$, non-COPD group $(r 2=0.343, P<0.001)$ and COPD group $(r 3=0.686, P<0.001)$. (B) Relationship between FEV1/FVC measured by spirometry and FEV6/FVC measured by COPD-6® in groups of GOLD stage I $(r l=0.197, P<0.044)$, stage II $(r l l=0.641, P<0.001)$, stage $I I I(r l l=0.715, P<0.001)$ and stage IV ( $r \mathrm{IV}=0.784, \mathrm{P}=0.117)$. (C) Bland-Altman graph of FVC by spirometry and FEV6 by COPD-6®.
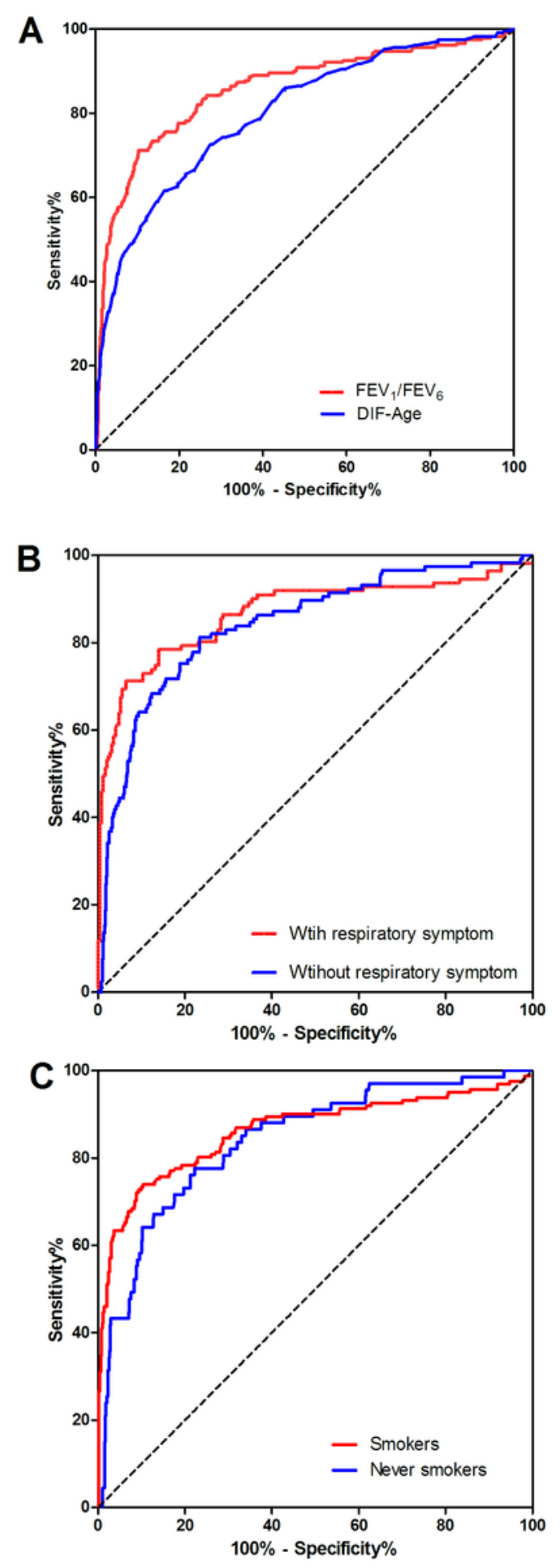

Figure 4 
Area under ROC curves for FEV1/FEV6 measured by COPD-6 (A) FEV1/FEV6 by COPD-6® and DIFAge("lung age" by COPD- $6 \AA$-actual age) to identify airflow obstruction.(B) FEV1/FEV6 by COPD- $6 \AA$ to identify airflow obstruction in the population with respiratory symptoms and the population without respiratory symptom. (C) FEV1/FEV6 by COPD-6® to identify airflow obstruction in the smokers (including current smokers and ex-smokers) and never-smokers. Using post-bronchodilators FEV1/FVC $<70 \%$ as a "gold standard" for determination of airflow obstruction.
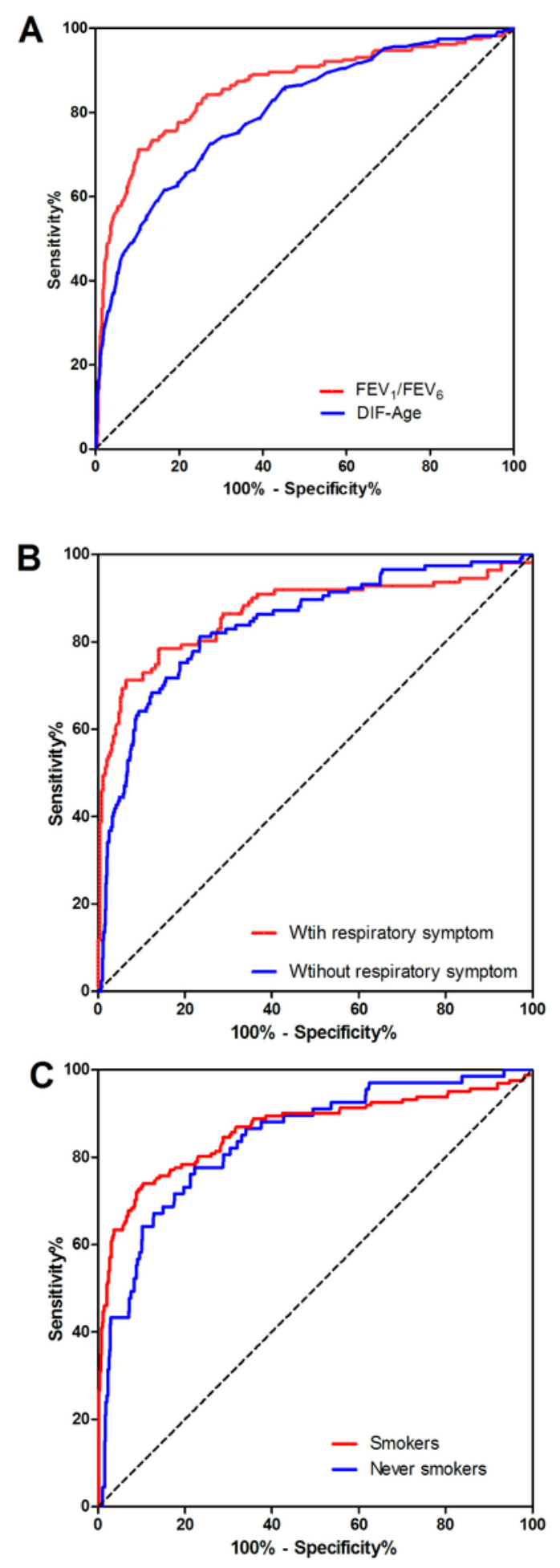

Figure 4 
Area under ROC curves for FEV1/FEV6 measured by COPD-6 (A) FEV1/FEV6 by COPD-6® and DIFAge("lung age" by COPD- $6 \AA$-actual age) to identify airflow obstruction.(B) FEV1/FEV6 by COPD- $6 \AA$ to identify airflow obstruction in the population with respiratory symptoms and the population without respiratory symptom. (C) FEV1/FEV6 by COPD-6® to identify airflow obstruction in the smokers (including current smokers and ex-smokers) and never-smokers. Using post-bronchodilators FEV1/FVC $<70 \%$ as a "gold standard" for determination of airflow obstruction.
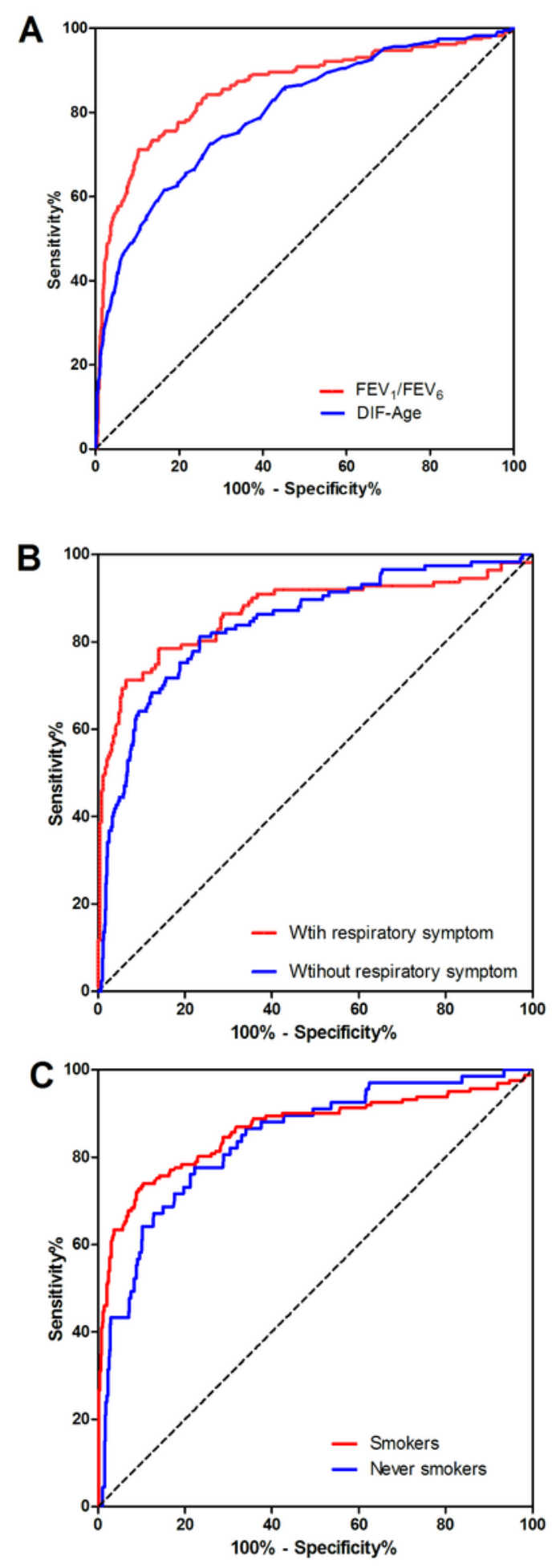

Figure 4 
Area under ROC curves for FEV1/FEV6 measured by COPD-6 (A) FEV1/FEV6 by COPD-6® and DIFAge("lung age" by COPD-6®-actual age) to identify airflow obstruction.(B) FEV1/FEV6 by COPD-6® to identify airflow obstruction in the population with respiratory symptoms and the population without respiratory symptom. (C) FEV1/FEV6 by COPD-6® to identify airflow obstruction in the smokers (including current smokers and ex-smokers) and never-smokers. Using post-bronchodilators FEV1/FVC $<70 \%$ as a "gold standard" for determination of airflow obstruction. 